\title{
O uso das tecnologias da informação e comunicação como ferramenta de gestão do conhecimento numa escola indígena
}

\author{
Angela Paula Drawanz Götzke - angela.gotzke@ifsc.edu.br - IFSC Jaqueline \\ Josiwana Steffens da Rocha - jaqueline.steffens@ifsc.edu.br - IFSC Simone \\ Meister Sommer Bilessimo - simone.bilessimo@ufsc.br - UFSC Juarez Bento \\ da Silva - juarez.b.silva@ieee.org - UFSC
}

Resumo. O conhecimento tradicional indígena historicamente é transmitido de forma oral entre seus pares. Muitos indígenas ainda resistem e lutam pela valorização da sabedoria tradicional e ao mesmo tempo desejam apropriar-se das novas tecnologias para documentar o conhecimento que vem se perdendo ao longo do tempo. Sendo assim, o objetivo desse artigo foi caracterizar o processo de conversão do conhecimento realizado em um projeto de extensão a fim de obter o registro da história e cultura guarani na Escola Indígena Nhu Porã, de Torres-RS, a partir do modelo SECI. Para tal empregou-se a pesquisa-ação e uma revisão da literatura com busca exploratória. $O$ trabalho mostrou de forma clara a presença das quatro etapas da conversão do conhecimento no contexto analisado, além da importância do uso e apropriação de ferramentas educacionais e tecnológicas que permitam o registro do conhecimento tradicional indígena da tribo Nhu Porã.

Palavras-chaves: Conhecimento tradicional indígena; Tecnologias da Informação e Comunicação; Cultura Guarani; Educação indígena.

\section{The use of information and communication technologies as a knowledge management tool in an indigenous school}

\begin{abstract}
Indigenous traditional knowledge is historically transmitted orally among peers. Many indigenous people still resist and fight for the valorization of traditional wisdom and at the same time wish to appropriate new technologies to document the knowledge that has been lost over time. Thus, the objective of this article was to characterize the process of knowledge conversion carried out in an extension project in order to obtain the registration of Guarani history and culture at the Nhu Porã Indigenous School, in Torres-RS, based on the SECI model. For this, we used action research and a literature review with exploratory search. The work clearly showed the presence of the four stages of knowledge conversion in the analyzed context, besides the importance of the use and appropriation of educational and technological tools that allow the registration of the indigenous traditional knowledge of the Nhu Porã tribe.
\end{abstract}

Keywords: Indigenous traditional knowledge; Information and Communication Technologies; Guarani culture; Indigenous education.

\section{Introdução}

De acordo com dados do Instituto Brasileiro de Geografia e Estatística (2010), a população indígena do Brasil é de aproximadamente 896,9 mil indivíduos, porém, 
somente parte deles está vivendo em aldeias indígenas. Apesar disso, as comunidades indígenas ainda resistem e lutam pela valorização da sabedoria tradicional e ao mesmo tempo desejam apropriar-se dos conhecimentos contemporâneos, a fim de construir um futuro melhor para a sua comunidade (MALDANER, 2016).

Sabe-se que tradicionalmente os indígenas transmitem seus conhecimentos de forma oral e com isso muitos dados, informação e conhecimento têm se perdido ao longo do tempo. Em outras palavras, esses saberes, que são parte do patrimônio histórico e cultural da humanidade, pelo fato de não serem registrados fisicamente acabam "morrendo" junto com as pessoas que os detêm (LAROQUE; SILVA, 2013).

Ao analisar a origem tácita do conhecimento tradicional indígena "sua codificação e consequentemente sua preservação tornam-se um grande desafio, e a sua transformação ou perda é um fato reconhecido" (NETTO, 2016, p. 341). Assim, Mello e Couto (2017) defendem que os indígenas terão maior probabilidade de reconhecimento quando conseguirem registrar/documentar seu patrimônio cultural material e imaterial, gerando um ciclo de gestão do conhecimento. Para isso, a gestão do conhecimento é uma importante ferramenta pois é considerada um conjunto de estratégias voltadas para criar, adquirir e compartilhar conhecimento (VALENTIM, 2008).

Desta forma, são necessárias alternativas que valorizem a cultura ameríndia e contribuam para a transformação do seu conhecimento tácito em explícito. Ou seja, é preciso transformar o conhecimento que está na mente das pessoas e foi adquirido no decorrer de suas experiências de vida em uma linguagem formal: documentos como livros, cartilhas, imagens, de modo que possam ser facilmente transmitidos para outras pessoas (NONAKA; TAKEUCHI, 1997).

Neste contexto, destaca-se que o problema dessa pesquisa está associado à inexistência e falta de domínio, por parte da comunidade da aldeia onde este trabalho foi realizado, de ferramentas e/ou metodologias que proporcionem a documentação do conhecimento tradicional, sejam elas físicas ou digitais.

Durante o desenvolvimento de atividades de extensão junto da Escola Indígena Nhu Porã, no município de Torres-RS, os professores indígenas da escola relataram a necessidade de documentar o conhecimento tradicional da comunidade. Após algumas reuniões com o cacique da aldeia e com a comunidade escolar, optou-se pela elaboração de um projeto de extensão, cuja finalidade foi registrar os saberes tradicionais e assim contribuir para a preservação da cultura Mbya Guarani.

Assim, a partir da confecção de um e-book que registra a história e cultura indígena da tribo Nhu Porã, este artigo pretende caracterizar o processo de conversão do conhecimento realizado no projeto, a partir do modelo SECI.

\section{Referencial Bibliográfico}

\subsection{A Gestão do Conhecimento e o Modelo SECI}

O conhecimento é inerente ao ser humano, Davenport e Prusak (1998, p.05) o definem como "uma mistura de experiência, valores, informação contextualizada e insight experimentado que fornece um modelo para avaliação e incorporação de novas experiências, sendo originado e aplicado na cabeça dos conhecedores".

Segundo Nonaka e Takeuchi (1997), o conhecimento é um processo dividido em duas dimensões: a ontológica e a epistemológica. $\mathrm{Na}$ dimensão ontológica, o conhecimento tem origem no indivíduo, ocorre na interação social de um grupo e acaba extrapolando os limites da organização. Com relação à dimensão epistemológica, cada indivíduo reflete sobre o conhecimento que produziu sobre ele mesmo, sobre as etapas, 
os limites e a validade prática da sua produção. Nessa dimensão o conhecimento é dividido em tácito e explícito.

O conhecimento tácito é pessoal, relativo ao contexto de cada indivíduo e precisa de grande esforço para ser formulado e comunicado. Já o conhecimento explícito ou codificado, diz respeito ao conhecimento que é transmitido por meio de linguagem formal e sistematizada (NONAKA; TAKEUCHI, 1997).

A gestão do conhecimento é um método de ordem prática que é empregado em projetos desenvolvidos com base no conhecimento e na sua constituição nas organizações (YU; ZHOU, 2015). O exame das várias características do processo de gestão do conhecimento, permite distribuí-los em quatro categorias: aquisição de conhecimento, aplicação do conhecimento, proteção do conhecimento e conversão de conhecimento (GOLD; MALHOTRA; SEGARS, 2001).

Nonaka e Takeuchi (1997, p.67) elaboraram um sistema de conversão do conhecimento originado em um "pressuposto crítico de que o conhecimento humano é criado e expandido através da interação social entre o conhecimento tácito e o conhecimento explícito". O modelo associa quatro formas de conversão do conhecimento: socialização, externalização, combinação e internalização e é chamado de modelo SECI. Conforme este modelo, a criação do conhecimento acontece de forma constante e dinâmica através da interação entre o conhecimento tácito e explícito e percorre quatro processos de conversão do conhecimento (NONAKA; TAKEUCHI, 1997).

A Socialização é o compartilhamento do conhecimento tácito, ou seja, de experiências práticas, por meio da imitação, gerando o conhecimento compartilhado. A Externalização compreende a transformação do conhecimento tácito em conhecimento explícito, gera conhecimento conceitual (NONAKA; TAKEUCHI, 1997).

A Combinação é o processo de sistematização dos conceitos. O processamento, edição, troca e combinação do conhecimento explícito geram novos conhecimentos, o conhecimento sistêmico. A Internalização ocorre quando o conhecimento explícito é incorporado à prática, é o aprender fazendo. $\mathrm{O}$ conhecimento explícito é convertido em conhecimento tácito, levando ao conhecimento operacional (NONAKA; TAKEUCHI, 1997). A Figura 1 ilustra como ocorrem os processos de conversão do conhecimento:

Figura 1 - Características da espiral do conhecimento

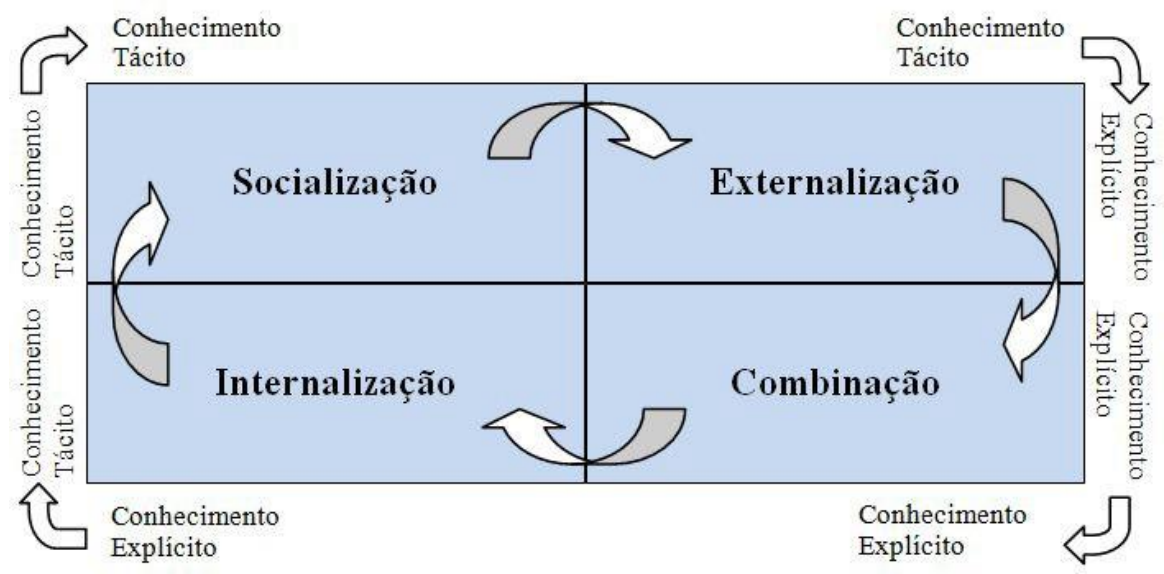

Fonte: Adaptado de Nonaka e Konno (1998, p.43).

Assim, percebe-se que ao percorrer os quatro processos de conversão, a criação do conhecimento desenvolve uma trajetória em forma de espiral. E, cada vez que o 
promove a amplificação dos conhecimentos (TAKEUCHI; NONAKA, 2008).

\subsection{O Conhecimento Tradicional Indígena e as Tecnologias da Informação e Comunicação}

Define-se como povos indígenas aqueles que se auto identificam como tais e desejam preservar, desenvolver e passar para seus descendentes a sua identidade cultural e social, ou seja, os seus conhecimentos tradicionais (PEREIRA; DIEGUES, 2010)

Os saberes tradicionais são aqueles que tratam do conhecimento local, ou seja, está intimamente relacionado à cultura e hábitos sociais que acontecem de forma natural, sem a necessidade de esforço extra das comunidades e das pessoas para existir (SANTILLI, 2005, p. 192). Esses conhecimentos são "um modo de produzir inovações e transmitir conhecimentos por meio de práticas específicas" (GALLOIS, 2000, p. 57). O aprendizado indígena acontece de forma tácita, por meio da vivência, da observação, com o contato direto com a natureza, as crianças aprendem brincando, indo caçar c, cultivando a roça, fazendo artesanato, fazendo o fogo (MATO, 2009).

$\mathrm{O}$ conhecimento tradicional tem como característica a originalidade e pouca modificação ao longo do tempo e permanece vinculado aos grupos onde tiveram origem (NETTO, 2016). Ocorre que com a proximidade das comunidades indígenas com elementos externos à sua cultura, muitos saberes tradicionais se perdem ao longo do tempo, seja pela influência de outras culturas, pela morte das pessoas mais velhas das tribos ou pela falta de registro documental/explícito (NETTO, 2016).

Dessa maneira, se as comunidades indígenas puderem se apropriar e fazer o uso de ferramentas que lhes permitam a documentação de seu patrimônio cultural material e imaterial, a manutenção e/ou transmissão desses conhecimentos entre seus pares, e até mesmo para os não indígenas, será facilitada (MELLO; COUTO, 2017). Para isso, as Tecnologias da Informação e Comunicação (TIC) podem contribuir de forma substancial, pois possibilita o acesso às informações de forma mais rápida e permite $\mathrm{o}$ registro permanente da informação, seja ela por meio físico ou digital, como e-books, vídeos, áudios, cartilhas e livros por exemplo.

De acordo com Pinto (2010), os novos utensílios tecnológicos como revistas eletrônicas, recursos audiovisuais, livros e internet, vêm causando mudanças no modo de viver dos povos indígenas, pois sua cultura até então era predominantemente ágrafa e oral. Com a ausência de qualquer tipo de registro e armazenamento físico, percebe-se a escassez de material escrito como forma de preservação cultural. Assim, proporcionar a esses indivíduos o acesso às novas tecnologias vai além de simplesmente capacitá-los para usar as redes sociais, "mas sim promover uma mudança com foco na preservação de sua identidade cultural em especial de seu vocabulário, história e cultura" (MENDONÇA, 2015, p. 126).

Logo, o uso das TIC nas comunidades indígenas requer o desenvolvimento de novas competências quanto ao domínio dessas ferramentas e sua utilização para preservar e promover o fortalecimento da língua e cultura tradicionais (VALADARES; BRAGA; BARBIN, 2005).

\section{Procedimentos Metodológicos}


conhecimento passa por um dos processos de conversão ele sofre um incremento o que desenvolvidas no projeto de extensão, empregou-se a pesquisa-ação, que "procura unir a pesquisa à ação ou prática, isto é, desenvolver o conhecimento e a compreensão como parte da prática" (ENGEL, 2000, p. 182). Ela permite "tornar o processo de pesquisa um processo de aprendizagem para todos os participantes e a situação problemática é interpretada a partir do ponto de vista das pessoas envolvidas" (FERENHOF; FERNANDES, 2016).

Durante a execução do projeto buscou-se caracterizar as etapas do processo de conversão do conhecimento nas atividades desenvolvidas. Para isso foi realizada uma revisão da literatura com busca exploratória. Na busca exploratória, também conhecida como revisão narrativa, não existem critérios explícitos, a busca por fontes é feita sem seguir uma lógica preestabelecida (FERENHOF; FERNANDES, 2016).

O projeto intitulado História Ilustrada: relatos da cultura e história Mbyá Guarani sob a ótica indígena foi desenvolvido durante o ano de 2018 e teve fomento do Instituto Federal de Santa Catarina - IFSC (Edital PROEX 04/2019) e da Universidade Federal de Santa Catarina - UFSC (Bolsa Cultura UFSC - Editais: 007/2017/UFSC e 001/2019/UFSC). A Figura 2 apresenta as etapas desenvolvidas durante o projeto.

Figura 2 - Etapas do projeto
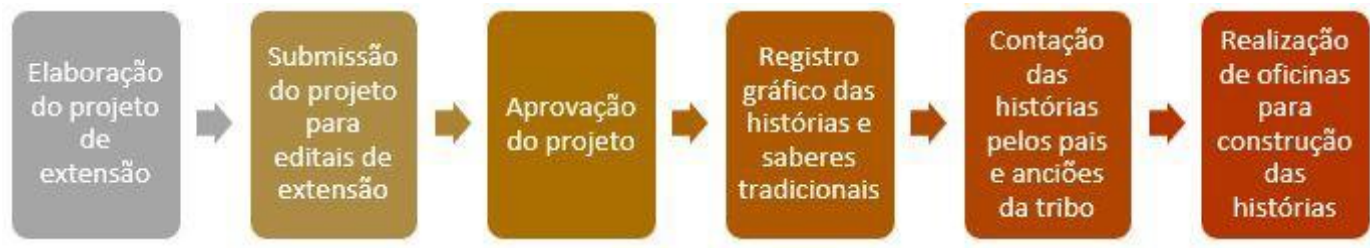

Fonte: Elaborada pelos autores (2019).

Participaram do projeto dois professores, um que leciona a disciplina de português e outro que trabalha a disciplina de língua, arte e cultura guarani, e 25 alunos indígenas de uma classe multisseriada da quarta até sétima série do ensino fundamental.

Os alunos foram os protagonistas na construção das histórias, e foram instruídos pelos professores indígenas a buscar as histórias junto dos anciãos da aldeia. Após ouvirem os relatos dos mais idosos, os estudantes registraram as histórias e os saberes tradicionais por meio de desenhos e textos na língua guarani. Posteriormente, um dos professores indígenas fez a tradução dos textos para a língua portuguesa.

\section{Resultados e Discussão}

Inicialmente, para que os alunos pudessem compreender a importância do projeto proposto, o professor indígena durante a disciplina de Arte e Cultura Guarani, falou para a turma sobre a forma tradicional do conhecimento da tribo e destacou a necessidade de salvaguardar os saberes tradicionais, de forma que as próximas gerações possam ter acesso e conhecer as práticas culturais da comunidade.

Em seguida, foram desenvolvidas oficinas de confecção de histórias em quadrinhos, onde os alunos tiveram o primeiro contato com um gibi, aprenderam como se dá o processo de construção de uma história: enredo, personagens, contexto/cenário, onomatopeias, balões de fala, diagramação/divisão dos quadros. Terminada essa fase, os alunos construíram suas próprias histórias, a partir dos conhecimentos prévios que tinham a respeito do dia a dia na aldeia. 
Noutro momento, com o uso de tablets, os alunos elaboraram uma história em quadrinhos onde eles foram os personagens, utilizando o aplicativo "Add Text to Photo"e "Mundo Gaturro Quadrinhos" para edição das imagens. Na ocasião os discentes encenaram e fotografaram o processo de plantio da mandioca, atividade tradicional da aldeia e que é cultivada há séculos. Apesar de esse ter sido o primeiro contato com a tecnologia para a maioria dos alunos, todos apresentaram desenvoltura e rapidez no aprendizado e manuseio da ferramenta.

Outra atividade realizada foi uma oficina de contação de histórias, onde os pais foram para a escola e contaram para seus filhos como foi o processo histórico da constituição da tribo. Essa atividade foi realizada na língua guarani, pois os pais se comunicam com os filhos usando a língua nativa. Após ouvir as histórias os alunos fizeram o registro do que haviam acabado de ouvir de seus pais.

$\mathrm{Na}$ sequência, o trabalho envolveu a participação dos anciãos da tribo. $\mathrm{Na}$ oportunidade, os alunos saíram da sala de aula e foram até a casa do Sr. Germano, uma das pessoas mais velhas da comunidade. Sempre usando a língua guarani, Germano contou para as crianças a forma tradicional que os meninos e meninas são criados dentro da cultura indígena, das práticas de caça e pesca, culto a Nhanderu (o Deus Guarani), além de destacar a importância das crianças não perderem suas raízes e tradições.

De volta para a escola, os alunos fizeram os registros das histórias que ouviram, sempre sob a orientação do professor indígena, que durante todo o tempo orientou os alunos sobre a escrita e uso da língua nativa para contar e registrar a história.

A partir dessas iniciativas, alguns pais começaram a participar do cotidiano escolar dos seus filhos com mais frequência, tornando-se comum a presença paterna/materna em sala de aula. Em muitas ocasiões eles sentaram ao lado de seus filhos e os ajudavam no registro do cotidiano da aldeia, mostrando interesse e preocupação em registrar os fatos da maneira mais fidedigna possível.

Posteriormente, foi realizada a editoração e diagramação do livro, onde os colaboradores do projeto de extensão editaram as histórias. Nessa etapa o professor indígena teve um papel fundamental, pois foi preciso fazer a correção do que os alunos registraram na língua guarani e também a tradução para a língua portuguesa, visto que o livro é bilíngue. O livro produzido servirá como ferramenta para auxiliar no ensino da língua, arte e cultura indígena, além de contribuir para a preservação e divulgação do conhecimento tradicional da Tribo Nhu Porã.

O lançamento oficial do livro, História Ilustrada: relatos da cultura e história Mbya Guarani sob a ótica indígena, ocorreu durante a Semana Nacional de Ciência e Tecnologia/2019 promovida pelo câmpus Araranguá do IFSC. Na ocasião, os alunos, o professor indígena e o cacique falaram para os alunos do IFSC e demais escolas visitantes da importância do trabalho realizado:

Isso é importante para que o branco conheça a nossa versão da história, como vivemos e o que ensinamos para nossos filhos. Muitas vezes o branco acha que o índio é bicho do mato, que vive pelado, mas faz tempo que as coisas mudaram. Hoje já usamos as coisas da cidade, vamos no mercado, no médico, usamos celular e nem por isso deixamos de ser índios. Nos preocupamos em ensinar para as crianças as tradições da nossa gente e esse livro vai deixar registrado para que todo mundo conheça. Isso vai contribuir para a preservação da nossa língua e nosso conhecimento e ficará registrado para sempre (Professor Indígena, 2019). 
O livro será impresso para ser distribuído nas escolas da região e ficará disponível para download gratuito na página do Laboratório de Experimentação Remota da UFSC (RExLab) no endereço https://rexlab.ufsc.br/projects-with-partners/. Na Figura 3 pode-se observar a capa e uma das páginas do livro desenvolvido.

Figura 3 - Imagens do livro produzido

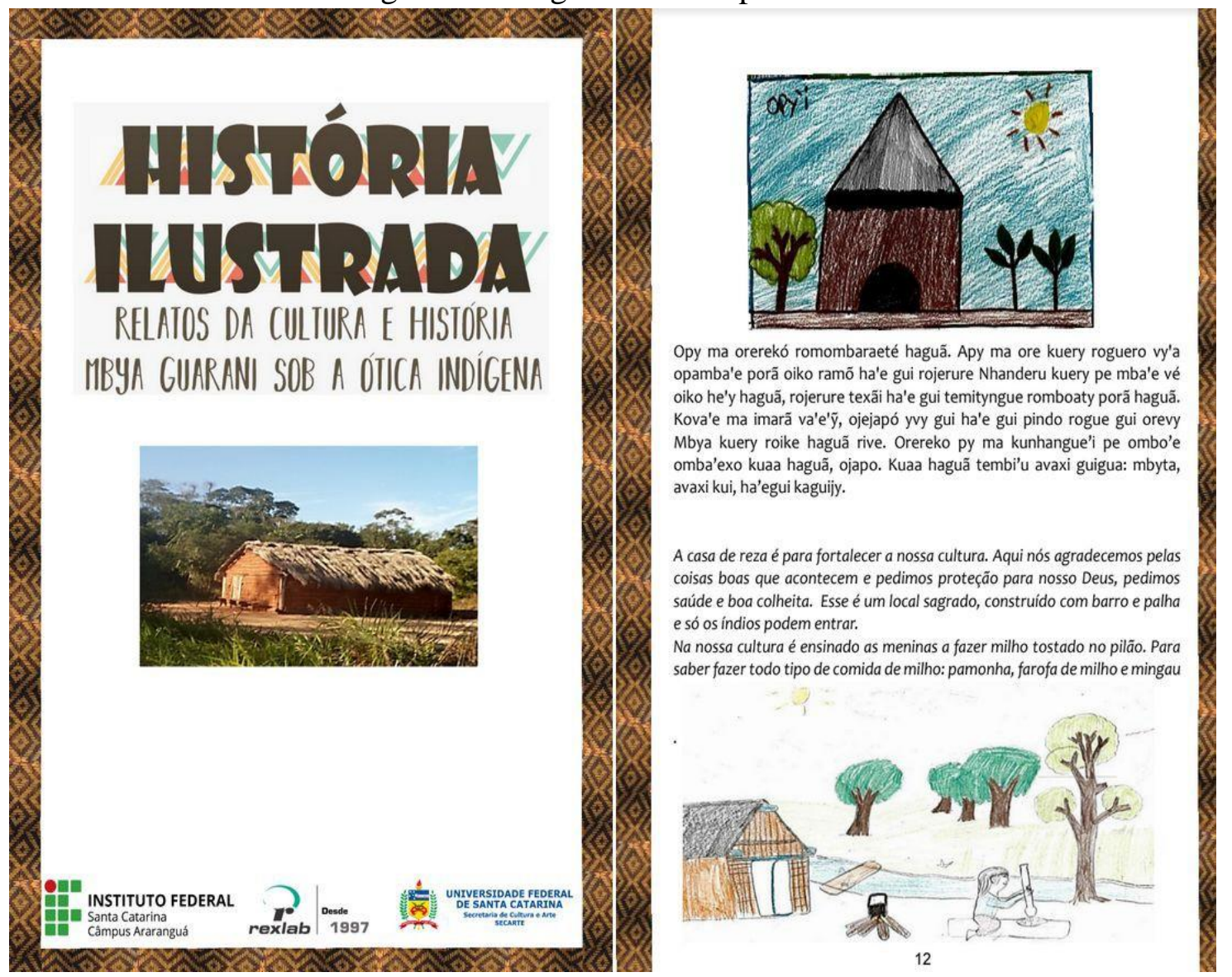

Fonte: Elaborada pelos autores (2019).

Ao analisar o desenvolvimento das etapas do projeto realizado e o livro produzido, a partir dos quatro processos de conversão do conhecimento do modelo SECI proposto por Nonaka e Takeuchi (1997), é possível tecer as seguintes observações:

A Socialização aconteceu na etapa das oficinas para construção da história em quadrinhos e contação de histórias, quando os estudantes ouviram seus pais e os anciãos relatando a história, arte e cultura da tribo. Nesse momento, houve interação e compartilhamento das experiências, ideias e percepções, ou seja, compartilhamento do conhecimento, conversão de conhecimento tácito em tácito.

À medida que o conhecimento tácito, compartilhado de forma oral durante a contação de histórias, foi registrado nos desenhos e histórias escritas na língua guarani, percebe-se a conversão do conhecimento tácito em explícito. Assim, a Externalização possibilitou que o conhecimento tácito fosse formalizado com a produção do livro.

A Combinação ocorreu quando os desenhos feitos pelos alunos (aqui já tratados como conhecimento explícito) foram selecionados para compor o livro. Em seguida, foi realizada a diagramação, escrita e tradução das informações contidas nos desenhos, o que gerou um novo conhecimento (explícito para explícito). 
No projeto, é possível perceber a internalização do conhecimento adquirido pela equipe executora, quando os professores, coordenador e bolsistas receberam o conhecimento explícito (desenhos e história escrita) e o transformaram em conhecimento tácito, apropriando-se dos saberes que foram adquiridos nas etapas de socialização, externalização, combinação, alcançando a internalização. Já os alunos puderam internalizar os novos conhecimentos gerados a partir dos desenhos que foram feitos pelos outros colegas (cada um com sua visão de mundo), pois cada um registrou uma história diferente, que ouviu do pai, da mãe, do professor ou dos anciãos da tribo.

\section{Conclusões}

Este artigo buscou caracterizar o processo de conversão do conhecimento realizado no projeto "História Ilustrada: Relatos da cultura e história Mbya Guarani sob a ótica indígena", a partir do modelo SECI de Nonaka e Takeuchi (1997). Durante a análise, foi possível perceber claramente as etapas da conversão do conhecimento no contexto analisado: socialização, externalização, combinação e internalização.

A presença semanal na escola possibilitou constatar que muitas das práticas da medicina tradicional, artesanato, crenças, lendas, jogos e hábitos alimentares ainda se mantêm vivos na aldeia. Para os indígenas a educação vai muito além da sala de aula, ela é vista como indispensável no processo de transmissão do conhecimento tradicional. Nesse sentido, a Escola tem um papel importante, visto que é bilíngue e conta com professores indígenas que trabalham a alfabetização e a língua, arte e cultura guarani, o que contribui para a preservação da cultura local.

Há muito ainda para se aprender sobre a riqueza cultural das populações indígenas, que apesar do histórico processo de exploração desde a chegada do homem branco ao continente, ainda resiste. Essa diversidade cultural sofre com a influência do mundo contemporâneo, e aos poucos a cultura tradicional está se adaptando, se reinventando, mas sem perder sua essência.

As novas formas de pensar e agir em sociedade desses ameríndios abrem espaço para que os aparatos tecnológicos e novas metodologias de ensino, aprendizagem e gestão do conhecimento sejam utilizados por eles de forma benéfica. Isso não significa o abandono de uma cultura secular, mas sim a apropriação tecnológica a fim de produzir novas formas de documentar e propagar o conhecimento tradicional.

Assim, conclui-se que a gestão do conhecimento aliada ao uso adequado das tecnologias da informação e comunicação é uma importante ferramenta que permite criar, adquirir e compartilhar conhecimento. A metodologia utilizada neste trabalho caracteriza-se como inovadora dentro do contexto estudado e permite que toda a comunidade, indígena ou não, tenha acesso à história e cultura da tribo registrada.

\section{Agradecimentos}

Ao IFSC e à UFSC pelo financiamento do projeto (Editais: Edital PROEX 04/2019/IFSC e Editais de Bolsa Cultura 007/2017/UFSC e 001/2019/UFSC), e à Escola Estadual de Educação Indígena Nhu Porã pela confiança e parceria.

\section{Referências Bibliográficas}


DAVENPORT, T. H.; PRUSAK, L. Conhecimento organizacional: como as organizações gerenciam seu capital o intelectual. $8^{\text {a }}$ ed. Rio de Janeiro: Campus, 1998.

ENGEL, G. I. Pesquisa-ação. Educar em Revista, n. 16, p. 181-191, 2000.

FERENHOF, H. A.; FERNANDES, R. F. Desmistificando a revisão de literatura como base para redação científica: método SSF. Revista ACB: Biblioteconomia em Santa Catarina, Florianópolis, v. 21, n. 3, p. 550-563, 2016. Disponível em: https://revista.acbsc.org.br/racb/article/view/1194/pdf. Acesso em: 20 abr. 2019.

GALLOIS, D. T. Sociedades indígenas e desenvolvimento: discursos e práticas, para pensar a tolerância. In: GRUPIONI, L. D. B.; VIDAL, L. B.; FISCHMANN, R. Povos indígenas e tolerância: construindo práticas de respeito e solidariedade. São Paulo: Edusp, 2001.

GOLD, A. H.; MALHOTRA, A.; SEGARS, A. H. Knowledge management: An organizational capabilities perspective. Journal of management information systems, v. 18, n. 1, p. 185-214, 2001. Disponível em:

https://www.tandfonline.com/doi/abs/10.1080/07421222.2001.11045669. Acesso em: 15 maio 2019.

IBGE. Censo 2010: Características Gerais dos Indígenas - Resultados do Universo. Rio de Janeiro: 2010. Disponível em:

http://www.ibge.gov.br/home/estatistica/populacao/censo2010/caracteristicas_gerais_in digenas/default_caracteristicas_gerais_indigenas.shtm. Acesso em: 01 maio 2019.

LAROQUE, L. F. S.; SILVA, J. B. S. Ambiente e cultura Kaingang: saúde e educação na pauta das lutas e conquistas dos Kaingang de uma terra indígena. Educ. rev., Belo Horizonte, v. 29, n. 2, p. 253-275, Jun 2013 . Disponível em:

http://www.scielo.br/scielo.php?script=sci_arttext\&pid=S0102-46982013000200011\&1 ng=en\&nrm=iso. Acesso em: 18 Maio 2019.

MATO, D. Diferenças culturais, interculturalidade e inclusão na produção de conhecimentos e práticas socioeducativas. In: CANDAU, V. L. (org.) Educação intercultural na América Latina: entre concepções, tensões e propostas. Rio de Janeiro: 7 Letras, p. 74-93, 2009.

MALDANER, Marcelo Pedro. Educação e cultura indígena guarani: práticas educacionais no colégio estadual indígena Teki Ñemoningo, Tekoha Ecoy. 2016. Dissertação (Mestrado em Integração Contemporânea da América Latina) - Programa de Pós-graduação em Integração Contemporânea da América Latina, Universidade Federal da Integração Latino-americana, Foz do Iguaçu/PR, 2016. Disponível em: http://dspace.unila.edu.br/123456789/691. Acesso em: 24 abr. 2019.

MELLO, R. P. S.; COUTO, I. H. P. As transformações da memória indígena na contemporaneidade. InCID: R. Ci. Inf. e Doc., v. 8, n. 2, p. 163-175, 2017.

MENDONÇA, D. O Uso da Tecnologia como Ferramenta de Compartilhamento e Preservação do Dialeto Indígena. In: Anais dos Workshops do Congresso Brasileiro de Informática na Educação. 2015. p. 125-134.

NETTO, M. Contexto e uso das mídias por populações indígenas brasileiras: elementos que podem contribuir para a preservação e disseminação do conhecimento tradicional em meios digitais e internet. 2016. Tese (Doutorado em Engenharia e Gestão do Conhecimento) - Programa de Pós-graduação em Engenharia e 
Gestão do Conhecimento, Universidade Federal de Santa Catarina, Florianópolis, 2016. Disponível em: https://repositorio.ufsc.br/xmlui/handle/123456789/167869. Acesso em: 24 abr. 2019.

NONAKA, I.; TAKEUCHI, H. Criação e dialética do conhecimento. In: NONAKA, I.; TAKEUCHI, H. Gestão do conhecimento. Tradução de Ana Thorell. Porto Alegre: Bookman, p. 17-38, 2008.

NONAKA, I.; TAKEUCHI, H. Criação de conhecimento na empresa. 19. ed. Rio de Janeiro: Elsevier, 1997.

NONAKA, I.; KONNO, N. The concept of "Ba": Building a foundation for knowledge creation. California management review, v. 40, n. 3, p. 40-54, 1998.

PEREIRA, B. E.; DIEGUES, A. C. Conhecimento de populações tradicionais como possibilidade de conservação da natureza: uma reflexão sobre a perspectiva da etnoconservação. Desenvolvimento e Meio ambiente, v. 22, 2010.

PINTO, A. A. Identidade/diversidade cultural no ciberespaço: práticas informacionais e de inclusão digital nas comunidades indígenas, o caso dos Kariri-Xocó e Pankararu no Brasil. Brasília, 2010. xix, 273 f. Tese (Doutorado em Ciência da Informação)- Faculdade de Ciência da Informação, Universidade de Brasília.

SANTILLI, J. Socioambientalismo e Novos Direitos: proteção jurídica à diversidade biológica e cultural. São Paulo: Peirópolis, 2005.

VALADARES, S. M. B.; BRAGA, A. O.; BARBIN, S. E. Tecnologias digitais como ferramentas para a manutenção e fortalecimento das línguas indígenas da Amazônia brasileira e áreas transfronteiriças. 2005. Disponível em:

http://bibliotecascruesp.usp.br/3sibd/docs/valadares144.pdf. Acesso em: 29 out. 2018.

VALENTIM, M. L. P. Gestão da Informação e Gestão do Conhecimento em ambientes organizacionais: conceitos e concepções. Tendências da Pesquisa Brasileira em

Ciência da Informação, v. 1, n. 1, p. 1-16, 2008. Disponível em: http://www.brapci.inf.br/_repositorio/2010/01/pdf_ea77bd91aa_0007779.pdf. Acesso em: 18 maio 2019.

YU, D.; ZHOU, R. Intellectual management: an integrative theory. Journal of the Knowledge Economy, v. 8, n. 3, p. 929-956, 2017. Disponível em: https://link.springer.com/article/10.1007\%2Fs13132-015-0305-0. Acesso em: 18 maio 2019. 